\title{
Antioxidant Effect of MnTE-2-PyP on Lung in Asthma Mice Model
}

\author{
Lyudmil Terziev, ${ }^{1}$ Violeta Dancheva, ${ }^{2}$ Veneta Shopova, ${ }^{2}$ and Galya Stavreva ${ }^{3}$ \\ ${ }^{1}$ Sector of Clinical Immunology and Allergology, Pelven Medical University, 5800 Pleven, Bulgaria \\ ${ }^{2}$ Sector of Disaster Medicine, Pelven Medical University, 5800 Pleven, Bulgaria \\ ${ }^{3}$ Sector of Clinical and Experimental Pharmacology, Pelven Medical University, 5800 Pleven, Bulgaria \\ Correspondence should be addressed to Lyudmil Terziev, luterzi@mail.bg
}

Received 20 October 2011; Accepted 28 December 2011

Academic Editors: R. Álvarez-Sala and F. Arancibia

Copyright ( $\odot 2012$ Lyudmil Terziev et al. This is an open access article distributed under the Creative Commons Attribution License, which permits unrestricted use, distribution, and reproduction in any medium, provided the original work is properly cited.

\begin{abstract}
Aim. To investigate the effects of MnTE-2-PyP on some markers of antioxidant defence system in asthma mice model. Material and Methods. The animals were divided into four groups: group 1, controls; group 2, injected with ovalbumin, group 3, treated with MnTE-2-PyP, and group 4, treated with ovalbumin and MnTE-2-PyP. The activities of superoxide dismutase, catalase, glutathione peroxidase and nonprotein sulfhydryl groups content (NPSH) were determined in lung homogenate. Results. The activities of superoxide dismutase and catalase in group 2 decreased significantly as compared to control group. The decrease of the same enzymes in group 4 was lower and significant as compared to group 2. Changes in the glutathione peroxidase activity showed a similar dynamics. The NPSH groups content decreased in group 2. In group 4 this decrease was relatively lower as compared to group 2. Conclusions. The application of MnTE-2-PyP mitigated the effects of oxidative stress in asthma mice model.
\end{abstract}

\section{Introduction}

Asthma is a major, worldwide health concern, affecting children and adults. It affects $7 \%$ of the US population and 300 million worldwide [1]. Currently in the USA, some 22 million people are reported to have asthma, six million of whom are children [2]. It is among the commonest chronic conditions in Western countries affecting 1 in 7 children and 1 in 12 adults (equivalent to 5.1 million people in the UK) and is responsible each year for 1500 avoidable deaths, as well as 20 million lost working days. The annual UK healthcare cost is estimated to be $£ 2.5$ billion [3]. Oxidative stress is believed to play a role in the development of number of human diseases such as cardiovascular disorders, immunologic diseases, cancer, and asthma. A large amount of epidemiological and clinical evidence exists to support the relationship between increased reactive oxygen species (ROS) and the pathogenesis of bronchial asthma [4-8]. Oxidative stress is a deleterious process that leads to lung damage and consequently to various lung diseases. To protect against exposure to oxidants the lungs have a powerful antioxidant system, including nonenzymatic and enzymatic antioxidants, which may delay or prevent oxidation, but also eliminate reactive oxygen species [5]. At high levels of oxidative stress, however, antioxidants become depleted, and an imbalance between oxidants and antioxidants occurs, which causes pathological damage, or a variety of cellular responses through formation of secondary ROS [9]. All the major varieties of inflammatory lung diseases, asthma, chronic obstructive pulmonary disease, idiopathic pulmonary fibrosis, acute respiratory distress syndrome, interstitial lung diseases, and bronchopulmonary dysplasia share a common feature of impaired oxidant/antioxidant ratio [10]. Therefore, the supplementation of antioxidants to boost the endogenous antioxidants or scavenge excessive ROS production could be utilized to prevent the inflammatory response in asthma by restoring oxidant-antioxidant balance. Current knowledge of the effects of oxidative stress allow the development of new classes of antioxidants in the treatment of asthma and other disorders, associated with the oxidative stress. Considerable progress has been made in the last years, in developing mitochondria-targeted antioxidants such as manganese porphyrins [2]. A number of water-soluble meso-substituted manganese porphyrins with a molecular weight above 800 quickly pass through the cell membranes and are distributed into the mitochondria $[11,12]$. 




FIgURe 1: Activity of superoxide dismutase in lung homogenate. Each point represents the mean \pm SEM for six mice.

Therefore we aimed to study the effect of MnTE-2-PyP (Manganese (III) 5,10,15,20-tetrakis (N-ethylpyridinium-2yl) porphyrin), a manganese-meso-porphyrin also known as AEOL-10113, on some markers of lung antioxidant defence system in asthma mice model.

\section{Material and Methods}

2.1. Chemicals. Ovalbumin, grade V and phosphate-buffered saline (PBS) were purchased from the Sigma-Aldrich Company and Imject Alum was obtained from Pierce Chemical Company (USA).

MnTE-2-PyP was kindly provided by Ines BatinićHaberle from the Department of Radiation Oncology, Duke University Medical Center, Durham, NC, USA.

2.2. Animals and Experimental Protocol. The experiment was performed in accordance with the Animal Welfare Regulations and was approved by the University Ethics Committee.

The study was carried out on 24 female $\mathrm{C} 57 \mathrm{Bl} / 6$ mice (weight $20 \pm 2.0 \mathrm{~g}, 8-10$ weeks old). The animals were raised at the university vivarium at a temperature of $22 \pm 2^{\circ} \mathrm{C}$ and humidity of $50 \pm 10 \%$, given normal pelleted diet and water ad libitum. The mice were divided into four groups: group 1 , controls; group 2 , injected with ovalbumin (OVA); group 3 , treated with MnTE-2-PyP; group 4, treated with OVA and MnTE-2-PyP. The animals from groups 1 and 3 were injected i.p. with a $100 \mu \mathrm{L}$ phosphate-buffed saline (PBS) + Imject Alum $(1: 1)$ on days 0 and 14 . The animals from groups 2 and 4 were injected with a $100 \mu \mathrm{L}$ ovalbumin solution, containing $20 \mu \mathrm{g}$ OVA on the same days. On days 24,25 , and 26, mice from groups 1 and 3 were given inhalation with PBS for $30 \mathrm{~min}$, and those from groups 2 and 4 were given inhalation with a $1 \%$ ovalbumin solution (OVA dissolved in PBS). For this purpose, a special plexiglass chamber was used. One hour before inhalation, and 12 hours later the animals from groups 1 and 2 were injected i.p. with $100 \mu \mathrm{L}$
PBS, and those from groups 3 and 4 received a $100 \mu \mathrm{L}$ MnTE2-Pyp dissolved in PBS, containing $5 \mathrm{mg} / \mathrm{kg}$, that is, the total daily dose was $10 \mathrm{mg} / \mathrm{kg}$. The experimental protocol was represented in Table 1.

The solution was sterilized by filtration through $0.2 \mu \mathrm{m}$ filters.

2.3. Biochemical Assays in the Lung Homogenate. The animals were sacrificed on day 28 (48 hours after the last inhalation) under thiopental anesthesia $(50 \mathrm{mg} / \mathrm{kg})$. The chest was opened and the lungs were perfused in situ via the right heart ventricle with saline $(10 \mathrm{~mL})$. The right lung was ligated at the hilus, cut, and then removed from the chest and used to prepare the lung homogenate. The tissue was homogenized with ice-cold $0.25 \mathrm{M}$ sucrose in Tris $\mathrm{HCl}$, $\mathrm{pH}=7.4$, in $1: 10$ ratio. The homogenate was centrifuged $(9000 \times \mathrm{g}, 30 \mathrm{~min})$, and the supernatant was stored on ice. The superoxide dismutase (SOD) activity in U/mg lung tissue was determined by the method of Maral et al. [13], and catalase (CAT) activity in mcat/g tissue was assessed by the method of Koroljuk et al. [14]. The activity of glutathione peroxidase (GP) in U/g lung tissue was measured by the method of Bernchnaider, modified by Pereslegina [15]. The non-protein sulfhydryl (NPSH) groups content in mol $\times$ $10^{7} / \mathrm{g}$ tissue was measured by the method of DeLucia et al. [16].

2.4. Statistical Analysis. Experimental data were analyzed using SPSS 14. When we tested for normality, two variablesGP and CAT showed non-parametric distribution, and we used medians, interquartile range and Mann-Whitney test for comparison. For the rest of the variable we applied posthoc ANOVA test and data were presented as mean \pm standard error of mean (SEM). $P<0.05$ were considered statistical significant.

\section{Results}

The activities of superoxide dismutase and catalase in group 2 (asthma-induced) decreased significantly in the lung homogenate up to $71 \%(P=0.001)$ and up to $77 \%$ $(P=0.004)$ respectively, as compared with the controls. The decrease of the same parameters in group 4 was lower $(92 \%, P=0.012)$ than that in group 2 and $91 \%(P=$ 0.006 ), statistically significant compared to the group 2 , respectively (Table 2, Figures 1 and 2). Changes in the glutathione peroxidase activity showed a similar dynamics, such as a decrease in the OVA group (68\%) and in the values approximate to those of the controls in group 4 . The decrease was $23 \%$ less than that in group 2 but it was non significant. (Table 2, Figure 3). The non-protein sulfhydryl (NPSH) groups content in the lung homogenate decreased up to $68 \%$ in group $2(P=0.015)$, and in the group treated with OVA and antioxidant (group 4) this decrease was relatively lower $(P=0.045)$ as compared to the OVA group (Table 2, Figure 4). The changes of the parameters in group 3 (MnTE-2-PyP alone) did not show significant changes compared to controls (Figures 1-4). 
TABLE 1: Experimental protocol.

\begin{tabular}{|c|c|c|c|}
\hline \multirow{2}{*}{ Groups } & \multicolumn{3}{|c|}{ Treatment } \\
\hline & Allergen & $\begin{array}{l}\text { Sensitization/exposure } \\
\quad(\text { on days } 0 \text { and } 14)\end{array}$ & $\begin{array}{l}\text { Exposure/challenge } \\
\text { (on days } 24,25 \text {, and 26) }\end{array}$ \\
\hline Group 1 & & Saline (i.p.) & $\begin{array}{l}\text { Saline inhalation for } 30^{\prime} \text {. Saline (i.p.) } 1 \text { hour before } \\
\text { nebulization and } 12 \text { hours later) }\end{array}$ \\
\hline Group 2 & OVA & OVA/alum (i.p.) & $\begin{array}{l}\text { OVA inhalation for } 30^{\prime} \text { Saline (i.p.) } 1 \text { hour before } \\
\text { nebulization and } 12 \text { hours later) }\end{array}$ \\
\hline Group 3 & & Saline (i.p.) & $\begin{array}{l}\text { Saline inhalation for } 30^{\prime} . \text { MnTE-2-PyP (i.p.) } 1 \text { hour } \\
\text { before nebulization and } 12 \text { hours later) }\end{array}$ \\
\hline Group 4 & OVA & OVA/alum (i.p.) & $\begin{array}{l}\text { OVA inhalation for } 30^{\prime} . \text { MnTE-2-PyP (i.p.) } 1 \text { hour } \\
\text { before nebulization and } 12 \text { hours later }\end{array}$ \\
\hline
\end{tabular}

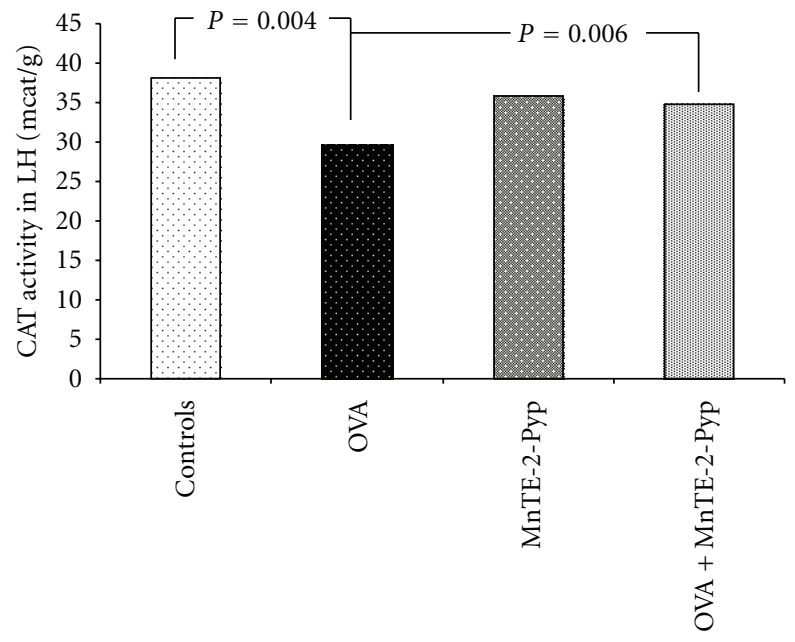

Figure 2: Activity of catalase in lung homogenate. Each point represents the median for six mice.

\section{Discussion}

The decrease of the activity of key antioxidant enzymes in the lung such as SOD, CAT and GP, as well as the level of the nonprotein sulfhydryl groups in animals injected and inhaled with OVA supports allegations that ovalbumin can provoke asthma, an oxidative stress-associated disease $[3,4,6,17]$. Some studies had revealed suppressed activity of catalase, superoxide dismutase and glutathione peroxidase in patients with bronchial asthma [18]. Comhair et al. also showed that the antioxidant enzymes (SOD and CAT) are in lower levels in asthmatic patients $[19,20]$. The activity of GPx has been found to be much lower in asthmatic children compared to normal children [21].

MnTE-2-PyP has a beneficial effect on the activity of studied antioxidant enzymes. Metalloporphyrins, and preferable water-soluble $\mathrm{Mn}$ complexes, remain the most stable and the most active prospective SOD mimetics [22]. That is way we chose and studied the effects of this compound. The activity of some manganese porphyrins approaches that of the SOD enzymes themselves [23]. Over the year, views of the researchers evolved from SOD mimics, to $\mathrm{O}_{2}{ }^{-} / \mathrm{ONOO}^{-}$ scavengers, and finally to redox modulators of cellular

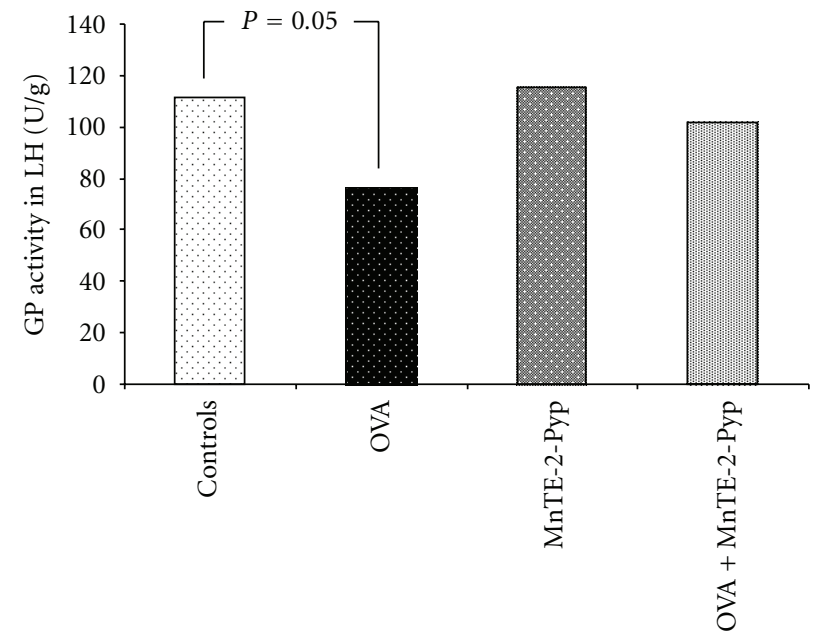

Figure 3: Activity of glutathione peroxidase in lung homogenate. Each point represents the median for six mice.

transcriptional activity [22]. Therefore they have at least four antioxidant properties, such as the removal of superoxide $\left(\mathrm{O}_{2}{ }^{-\bullet}\right)$, hydrogen peroxide $\left(\mathrm{H}_{2} \mathrm{O}_{2}\right)$, peroxinitrite $\left(\mathrm{ONOO}^{-}\right)$, and lipid peroxides $[24,25]$. Given i.p. to mice at $10 \mathrm{mg} / \mathrm{kg}$ MnTE-2-PyP ${ }^{5+}$ distributed into all organs studied (liver, kidney, spleen, lung, heart, and brain). It had high chances to enter mitochondria. At the upper dose MnTE-2-PyP injection was found in mitochondria at $2.9 \mathrm{ng} / \mathrm{mg}$ protein [26]. Such levels are high enough to protect mitochondria against peroxynitrite-mediated damage [27]. The plasma half-life is about $1 \mathrm{~h}$, and the organ half-life is about 60$135 \mathrm{~h}$ [22]. This explains why we have applied the antioxidant twice daily at intervals of 12 hours. The lack of decrease in activity of SOD in the group of animals, treated with OVA $+\mathrm{MnTE}-2-\mathrm{PyP}$ is explained by the fact that in vivo they will be readily reduced by cellular reductants, flavoenzymes, $\mathrm{NO}$, and so forth, to $\mathrm{Mn}(\mathrm{II}) \mathrm{P}[27,28]$, which will then in turn reduce $\mathrm{O}_{2}^{-}$to $\mathrm{H}_{2} \mathrm{O}_{2}$, acting as superoxide reductases rather than SOD [29]. Moreover all synthetic SOD mimics can scavenge peroxynitrite or its degradation products [22]. MnTE-2-PyP is 16-fold more prone to oxidative degradation than other Mn porphyrins, the commercial, MnTBAP [30]. 
TABLE 2: Effect of MnTE-2-PyP on the activity of some enzymes of lung antioxidant defence system in mice asthma model.

28 day after treatment (48 hours after the last inhalation)

\begin{tabular}{|c|c|c|c|c|}
\hline \multirow{2}{*}{ Parameters } & \multicolumn{4}{|c|}{ Groups } \\
\hline & Control & OVA & MnTE-2-PyP & $\mathrm{OVA}+\mathrm{MnTE}-2-\mathrm{PyP}$ \\
\hline $\begin{array}{l}\text { SOD activity in U/g } \\
\text { mean } \pm \text { SEM }\end{array}$ & $31.1 \pm 1.79$ & $22.1 \pm 1.94^{*}$ & $28.6 \pm 1.01$ & $28.6 \pm 1.25^{\dagger}$ \\
\hline CAT activity in mcat/g & 38.14 & $29.48^{*}$ & 35.91 & $34.81^{\dagger}$ \\
\hline Median (min-max) & $(33.08-44.12)$ & $(21.51-31.20)$ & $31.92-38.72$ & $31.69-43.51$ \\
\hline $\mathrm{Q}_{3}-\mathrm{Q}_{1}$ & 5.07 & 4.30 & 4.5 & 9.14 \\
\hline GP activity in U/g & 111.2 & $76.07^{*}$ & 115.3 & 101.5 \\
\hline Median (min-max) & $51.4-138.74$ & $66.85-83.56$ & $100.7-118.25$ & $62.27-136.92$ \\
\hline $\mathrm{Q}_{3}-\mathrm{Q}_{1}$ & 29.65 & 6.38 & 12.74 & 49.81 \\
\hline $\begin{array}{l}\text { NPSH groups in } \mathrm{mol} / \mathrm{g} 10^{-7} \\
\text { mean } \pm \mathrm{SEM}\end{array}$ & $0.58 \pm 0.03$ & $0.40 \pm 0.03^{*}$ & $0.54 \pm 0.084$ & $0.55 \pm 0.04^{\dagger}$ \\
\hline
\end{tabular}

OVA: ovalbumin; MnTE-2-PyP: Manganese (III) 5,10,15,20-tetrakis (N-ethylpyridinium-2-yl) porphyrin; SOD: superoxide dismutase; CAT: catalase; GP: glutathion peroxidase; NPSH groups: non protein sulfhydryl groups; $S E M$, standard error of mean; $\mathrm{Q}_{3}-\mathrm{Q}_{1}$ : interquartile range

* Different from control at $P<0.05$;

${ }^{\dagger}$ Different from group 2 (OVA) at $P<0.05$.

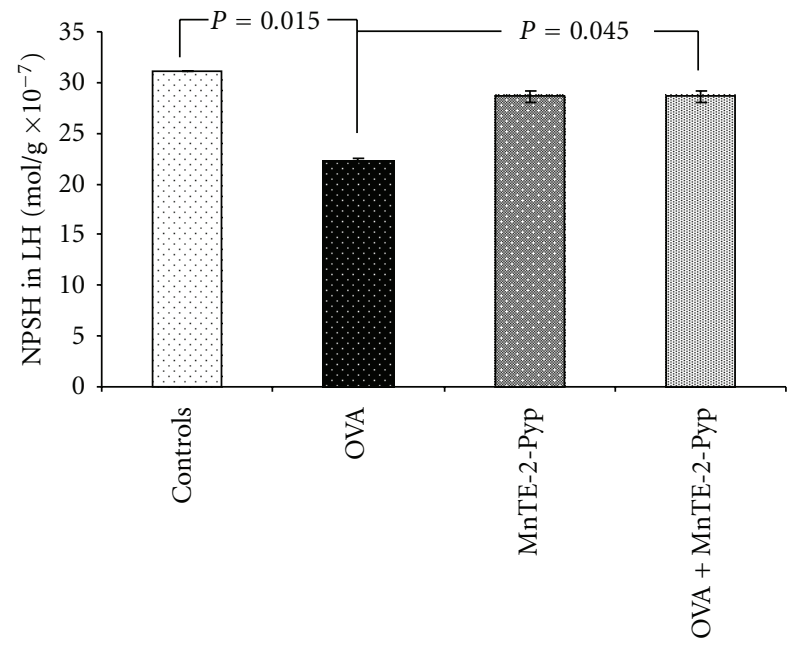

Figure 4: Content of nonprotein sulfhydryl groups in lung homogenate. Each point represents the mean \pm SEM for six mice.

The effects, observed after Mn porphyrins use, were the consequence not only of mere scavenging of ROS/RNS (reactive nitrogen species), but also of Mn porphyrins being able to modulate ROS/RNS-based signaling pathways. $\mathrm{Mn}$ (III) $\mathrm{N}$-alkylpyridylporphyrins inhibit in vitro and in vivo activation of several redox-controlled transcription factors such as HIF- $1 \alpha$ (hypoxia inducible factor $1 \alpha$ ), NF$\mathrm{kB}$ (nuclear factor kappa-B), AP-1 (activating protein-1), and SP-1 (specificity protein-1) [31, 32]. MnTE-2-PyP, a potent SOD mimic/ONOO ${ }^{-}$scavenger, can strongly inhibit excessive activation of redox-sensitive cellular transcriptional activity, particularly suppressing hypoxia inducible factor $1 \alpha$ (HIF-1 $\alpha$ ) activation [33]. This results in lowering the number of inflammatory cells and cytokines, which in turn could lower to the levels of secondary ROS/RNS [34]. Manganese meso-porphyrins have been used successfully to treat oxidative stress in the numerous disorders such as stroke [35], spinal cord injury [36], Parkinson disease [37], Alzheimer disease [38], diabetes [39], cancer [40, $41]$, ischemia/reperfusion conditions [42, 43], bronchopulmonary dysplasia [44], asthma [45, 46], lung fibrosis [47], lung radioprotection [48], and sepsis [49]. The recent study on the effects of antioxidants, especially mitochondriatargeted antioxidants, indicated that these compounds may potentially improve the treatment of widespread and socially significant diseases, such as asthma.

\section{Conclusion}

The intraperitoneal application of $5 \mathrm{mg}$ MnTE-2-PyP, a manganese meso-porphyrin, twice daily one hour before nebulization with ovalbumin on days 24,25 , and 26 mitigated the effects of the oxidative stress in asthma mice model assessed by key antioxidant enzymes and content of nonprotein sulfhydryl groups in the lungs. MnTE-2-PyP restored the basic antioxidant enzymes, such as superoxide dismutase, glutathione peroxidase as well as the content of the nonprotein sulfhydryl groups in the lungs.

\section{Acknowledgment}

This study was carried out with the financial support of Medical University-Pleven through the University Grants Commission (Project N 17/2009).

\section{References}

[1] C. H. Fanta, "Drug therapy: asthma," New England Journal of Medicine, vol. 360, no. 10, pp. 1002-1014, 2009.

[2] P. Hemachandra Reddy, "Mitochondrial dysfunction and oxidative stress in asthma: implications for mitochondriatargeted antioxidant therapeutics," Pharmaceuticals, vol. 4, no. 3, pp. 429-456, 2011. 
[3] S. T. Holgate, H. S. Arshad, G. C. Roberts, P. H. Howarth, P. Thurner, and D. E. Davies, "A new look at the pathogenesis of asthma," Clinical Science, vol. 118, no. 7, pp. 439-450, 2010.

[4] Y. S. Cho and H. B. Moon, "The role of oxidative stress in the pathogenesis of asthma," Allergy, Asthma and Immunology Research, vol. 2, no. 3, pp. 183-187, 2010.

[5] I. Rahman and W. MacNee, "Role of oxidants/antioxidants in smoking-induced lung diseases," Free Radical Biology and Medicine, vol. 21, no. 5, pp. 669-681, 1996.

[6] M. A. Riedl and A. E. Nel, "Importance of oxidative stress in the pathogenesis and treatment of asthma," Current Opinion in Allergy and Clinical Immunology, vol. 8, no. 1, pp. 49-56, 2008.

[7] H. Sugiura and M. Ichinose, "Oxidative and nitrative stress in bronchial asthma," Antioxidants and Redox Signaling, vol. 10, no. 4, pp. 785-797, 2008.

[8] P. Kirkham and I. Rahman, "Oxidative stress in asthma and COPD: antioxidants as a therapeutic strategy," Pharmacology and Therapeutics, vol. 111, no. 2, pp. 476-494, 2006.

[9] J. M. C. Gutteridge and B. Halliwell, "Free radicals and antioxidants in the year 2000. A historical look to the future," Annals of the New York Academy of Sciences, vol. 899, pp. 136$147,2000$.

[10] A. Nadeem, A. Masood, and N. Siddiqui, "Oxidantantioxidant imbalance in asthma: scientific evidence, epidemiological data and possible therapeutic options," Therapeutic Advances in Respiratory Disease, vol. 2, no. 4, pp. 215-235, 2008.

[11] Q. Y. Li, C. Pedersen, B. J. Day, and M. Patel, "Dependence of excitotoxic neurodegeneration on mitochondrial aconitase inactivation," Journal of Neurochemistry, vol. 78, no. 4, pp. 746-755, 2001.

[12] I. Spasojević, Y. Chen, T. J. Noel et al., "Mn porphyrin-based superoxide dismutase (SOD) mimic, MnIIITE-2-PyP5+, targets mouse heart mitochondria," Free Radical Biology and Medicine, vol. 42, no. 8, pp. 1193-1200, 2007.

[13] I. Maral, K. Puget, and H. Michelson, "Comparative study of SOD, catalase and GSH-Px levels in erythrocytes of different animals," Biochemical and Biophysical Research Communications, vol. 77, pp. 1532-1535, 1977.

[14] M. A. Koroliuk, L. I. Ivanova, I. G. Maĭorova, and V. E. Tokarev, "A method of determining catalase activity," Laboratornoe delo, no. 1, pp. 16-19, 1988 (Russian).

[15] I. A. Pereslegina, "The activity of antioxidant enzymes in the saliva of normal children," Laboratornoe Delo, no. 11, pp. 2023, 1989.

[16] A. J. Delucia, M. G. Mustafa, M. Z. Hussain, and C. E. Cross, "Ozone interaction with rodent lung-III. Oxidation of reduced glutathione and formation of mixed disulfides between protein and nonprotein sulfhydryls," Journal of Clinical Investigation, vol. 55, no. 4, pp. 794-802, 1975.

[17] R. Dworski, L. Jackson Roberts, J. J. Murray, J. D. Morrow, T. V. Hartert, and J. R. Sheller, "Assessment of oxidant stress in allergic asthma by measurement of the major urinary metabolite of $\mathrm{F}_{2}$-isoprostane, 15-F2t-IsoP (8-iso-PGF2 $\alpha$ )," Clinical and Experimental Allergy, vol. 31, no. 3, pp. 387-390, 2001.

[18] B. I. A. Varshavskii, G. V. Trubnikov, L. P. Galaktipmpva et al., "Oxidant-antioxidant status of patients with bronchial asthma during inhalation and systemic glucocorticoid therapy," Terapevticheskii Arkhiv, vol. 75, pp. 21-24, 2003 (Russian).

[19] S. A. A. Comhair, P. R. Bhathena, R. A. Dweik, M. Kavuru, and S. C. Erzurum, "Rapid loss of superoxide dismutase activity during antigen-induced asthmatic response," Lancet, vol. 355, no. 9204, p. 624, 2000.

[20] S. A. A. Comhair, K. S. Ricci, M. Arroliga et al., "Correlation of systemic superoxide dismutase deficiency to airflow obstruction in asthma," American Journal of Respiratory and Critical Care Medicine, vol. 172, no. 3, pp. 306-313, 2005.

[21] M. F. Liao, C. C. Chen, and M. H. Hsu, "Evaluation of the serum antioxidant status in asthmatic children," Acta Paediatrica Taiwanica, vol. 45, no. 4, pp. 213-217, 2004.

[22] I. Batinić-Haberle, J. S. Rebouças, and I. Spasojević, "Superoxide dismutase mimics: chemistry, pharmacology, and therapeutic potential," Antioxidants and Redox Signaling, vol. 13, no. 6, pp. 877-918, 2010.

[23] G. DeFreitas-Silva, J. S. Rebouças, I. Spasojević, L. Benov, Y. M. Idemori, and I. Batinić-Haberle, "SOD-like activity of $\mathrm{Mn}(\mathrm{II}) \beta$-octabromo-meso-tetrakis(N-methylpyridinium3-yl)porphyrin equals that of the enzyme itself," Archives of Biochemistry and Biophysics, vol. 477, no. 1, pp. 105-112, 2008.

[24] M. Patel and B. J. Day, "Metalloporphyrin class of therapeutic catalytic antioxidants," Trends in Pharmacological Sciences, vol. 20, no. 9, pp. 359-364, 1999.

[25] B. J. Day, "Catalytic antioxidants: a radical approach to new therapeutics," Drug Discovery Today, vol. 9, no. 13, pp. 557566, 2004.

[26] I. Spasojević, Y. Chen, T. J. Noel et al., "Mn porphyrinbased superoxide dismutase (SOD) mimic, MnIIITE-2-PyP ${ }^{5+}$, targets mouse heart mitochondria," Free Radical Biology and Medicine, vol. 42, no. 8, pp. 1193-1200, 2007.

[27] G. Ferrer-Sueta, L. Hannibal, I. Batinic-Haberle, and R. Radi, "Reduction of manganese porphyrins by flavoenzymes and submitochondrial particles: a catalytic cycle for the reduction of peroxynitrite," Free Radical Biology and Medicine, vol. 41, no. 3, pp. 503-512, 2006.

[28] G. Ferrer-Sueta, I. Batinić-Haberle, I. Spasojević, I. Fridovich, and R. Radi, "Catalytic scavenging of peroxynitrite by isomeric $\mathrm{Mn}(\mathrm{III}) \mathrm{N}$ - methylpyridylporphyrins in the presence of reductants," Chemical Research in Toxicology, vol. 12, no. 5, pp. 442-449, 1999.

[29] E. D. Coulter, J. P. Emerson, D. M. Kurtz, and D. E. Cabelli, "Superoxide reactivity of rubredoxin oxidoreductase (desulfoferrodoxin) from Desulfovibrio vulgaris: a pulse radiolysis study [25]," Journal of the American Chemical Society, vol. 122, no. 46, pp. 11555-11556, 2000.

[30] I. Batinić-Haberle, I. Spasojević, P. Hambright, L. Benov, A. L. Crumbliss, and I. Fridovich, "The relationship between redox potentials, proton dissociation constants of pyrrolic nitrogenes, and in vitro and in vivo superoxide dismutase activities of mamganese(III) and iron(III) cationic and anionic porphyrins," Inorganic Chemistry, vol. 38, pp. 4011-4022, 1999.

[31] I. L. Jackson, L. Chen, I. Batinic-Haberle, and Z. Vujaskovic, "Superoxide dismutase mimetic reduces hypoxia-induced O2, TGF- $\beta$, and VEGF production by macrophages," Free Radical Research, vol. 41, no. 1, pp. 8-14, 2007.

[32] B. J. Moeller, I. Batinic-Haberle, I. Spasojevic et al., "A manganese porphyrin superoxide dismutase mimetic enhances tumor radioresponsiveness," International Journal of Radiation Oncology Biology Physics, vol. 63, no. 2, pp. 545-552, 2005.

[33] B. Gauter-Fleckenstein, K. Fleckenstein, K. Owzar et al., "Early and late administration of $\mathrm{MnTE}-2-\mathrm{PyP}^{5+}$ in mitigation and treatment of radiation-induced lung damage," Free Radical Biology and Medicine, vol. 48, no. 8, pp. 1034-1043, 2010. 
[34] D. Salvemini, D. P. Riley, and S. Cuzzocrea, "SOD mimetics are coming of age," Nature Reviews Drug Discovery, vol. 1, no. 5, pp. 367-374, 2002.

[35] G. Burkhard Mackensen, M. Patel, H. Sheng et al., "Neuroprotection from delayed postischemic administration of a metalloporphyrin catalytic antioxidant," Journal of Neuroscience, vol. 21, no. 13, pp. 4582-4592, 2001.

[36] H. Sheng, I. Spasojevic, D. S. Warner, and I. BatinicHaberle, "Mouse spinal cord compression injury is ameliorated by intrathecal cationic manganese(III) porphyrin catalytic antioxidant therapy," Neuroscience Letters, vol. 366, no. 2, pp. 220-225, 2004.

[37] T. R. Golden and M. Patel, "Catalytic antioxidants and neurodegeneration," Antioxidants and Redox Signaling, vol. 11, no. 3, pp. 555-569, 2009.

[38] P. Sompol, W. Ittarat, J. Tangpong et al., "A neuronal model of Alzheimer's disease: an insight into the mechanisms of oxidative stress-mediated mitochondrial injury," Neuroscience, vol. 153, no. 1, pp. 120-130, 2008.

[39] J. D. Piganelli, S. C. Flores, C. Cruz et al., "A metalloporphyrinbased superoxide dismutase mimic inhibits adoptive transfer of autoimmune diabetes by a diabetogenic T-cell clone," Diabetes, vol. 51, no. 2, pp. 347-355, 2002.

[40] Y. Zhao, L. Chaiswing, T. D. Oberley et al., "A mechanismbased antioxidant approach for the reduction of skin carcinogenesis," Cancer Research, vol. 65, no. 4, pp. 1401-1405, 2005.

[41] A. Y. Makinde, X. Luo-Owen, A. Rizvi et al., "Effect of a metalloporphyrin antioxidant (MnTE-2-PyP) on the response of a mouse prostate cancer model to radiation," Anticancer Research, vol. 29, no. 1, pp. 107-118, 2009.

[42] H. Saba, I. Batinic-Haberle, S. Munusamy et al., "Manganese porphyrin reduces renal injury and mitochondrial damage during ischemia/reperfusion," Free Radical Biology and Medicine, vol. 42, no. 10, pp. 1571-1578, 2007.

[43] T. J. Wu, N. H. Khoo, F. Zhou, B. J. Day, and D. A. Parks, "Decreased hepatic ischemia-reperfusion injury by manganese-porphyrin complexes," Free Radical Research, vol. 41, no. 2, pp. 127-134, 2007.

[44] L. Y. L. Chang, M. Subramaniam, B. A. Yoder et al., "A catalytic antioxidant attenuates alveolar structural remodeling in bronchopulmonary dysplasia," American Journal of Respiratory and Critical Care Medicine, vol. 167, no. 1, pp. 57-64, 2003.

[45] L. Y. Chang and J. D. Crapo, "Inhibition of airway inflammation and hyperreactivity by a catalytic antioxidant," Chest, vol. 123, no. 3, p. 446, 2003.

[46] L. Y. Chang and J. D. Crapo, "Inhibition of airway inflammation and hyperreactivity by an antioxidant mimetic," Free Radical Biology and Medicine, vol. 33, no. 3, pp. 379-386, 2002.

[47] B. J. Day, "Antioxidants as potential therapeutics for lung fibrosis," Antioxidants and Redox Signaling, vol. 10, no. 2, pp. 355-370, 2008.

[48] Z. Vujaskovic, I. Batinic-Haberle, Z. N. Rabbani et al., "A small molecular weight catalytic metalloporphyrin antioxidant with superoxide dismutase (SOD) mimetic properties protects lungs from radiation-induced injury," Free Radical Biology and Medicine, vol. 33, no. 6, pp. 857-863, 2002.

[49] N. Nin, A. Cassina, J. Boggia et al., "Septic diaphragmatic dysfunction is prevented by $\mathrm{Mn}$ (III)porphyrin therapy and inducible nitric oxide synthase inhibition," Intensive Care Medicine, vol. 30, no. 12, pp. 2271-2278, 2004. 


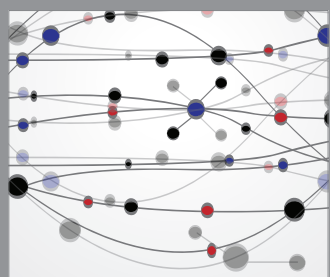

The Scientific World Journal
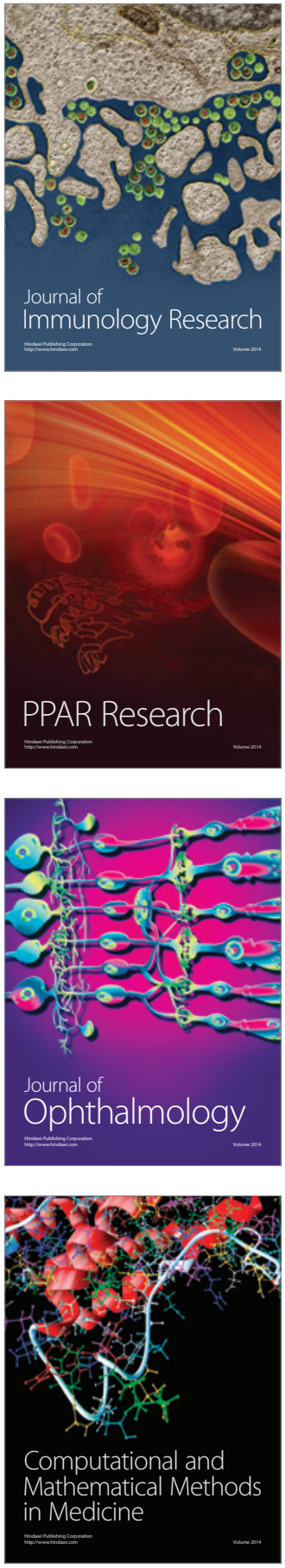

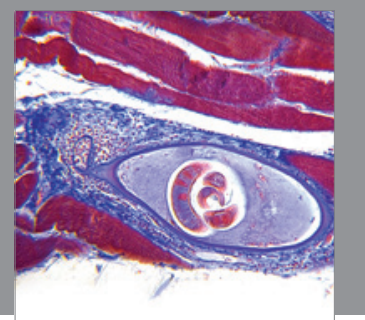

Gastroenterology

Research and Practice


\section{Hindawi}

Submit your manuscripts at

http://www.hindawi.com
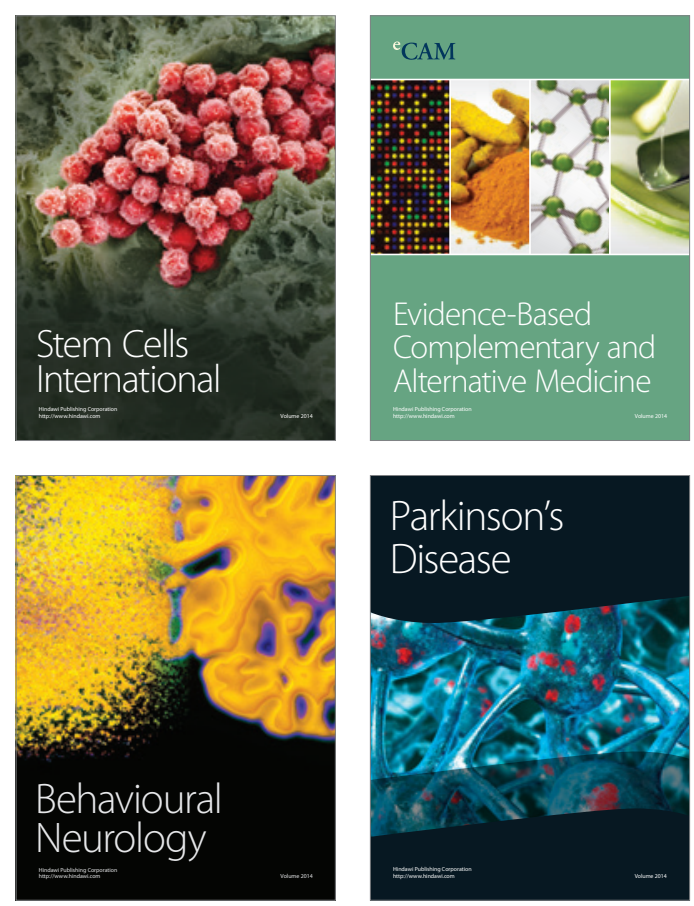

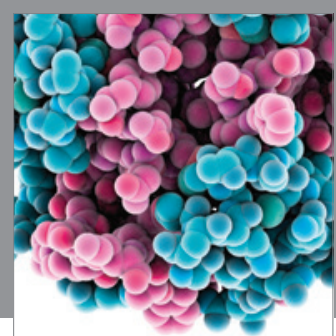

Journal of
Diabetes Research

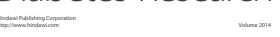



Disease Markers
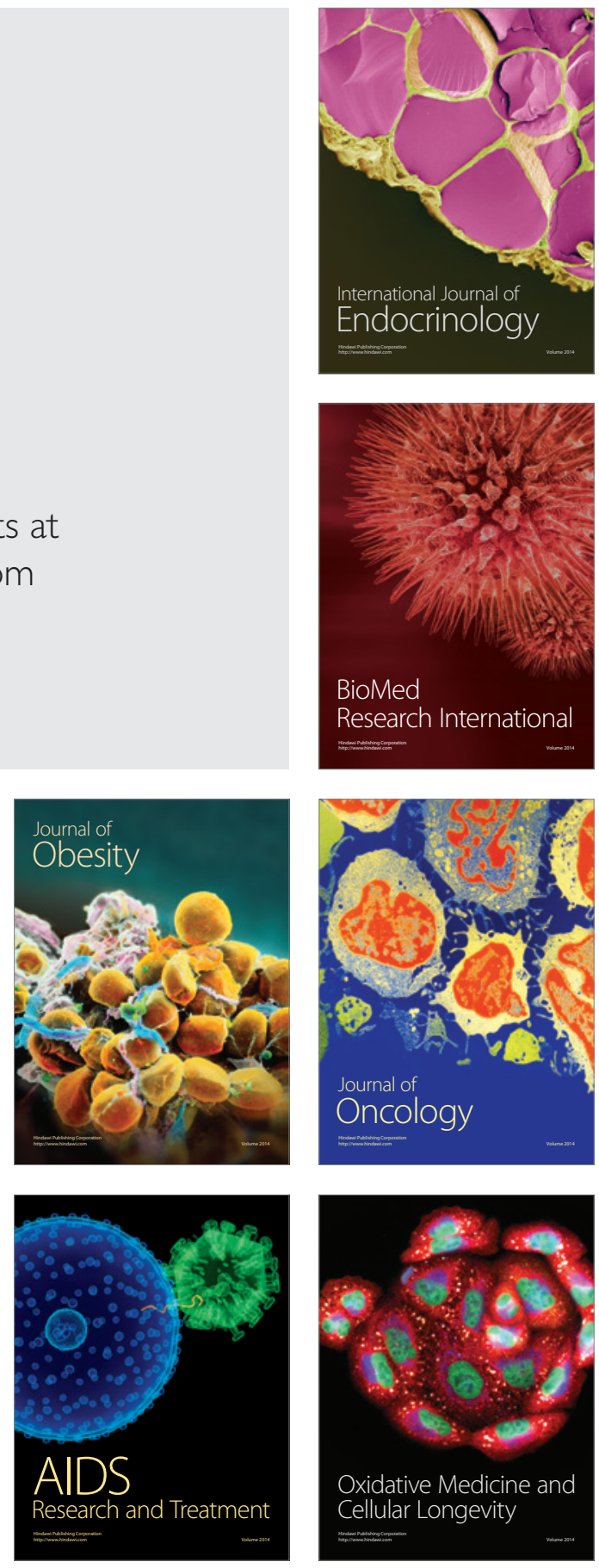